\title{
Displacement of submacular hemorrhage associated with age-related macular degeneration using vitrectomy and submacular tPA injection followed by intravitreal ranibizumab
}

\author{
This article was published in the following Dove Press journal: \\ Clinical Ophthalmology \\ 19 June 2010 \\ Number of times this article has been viewed
}

\section{Sukhpal Singh Sandhu', \\ Sridhar Manvikar ${ }^{\prime}$ \\ David Henry William Steel' \\ 'Sunderland Eye Infirmary, Sunderland, United Kingdom; ${ }^{2}$ Centre for Eye Research Australia, Melbourne, Australia}

Correspondence: David Henry William Steel

Sunderland Eye Infirmary, Queen Alexandra Road, Sunderland, SR2 9HP, UK Tel +44 I9I 5699065

Fax +44 I9I 5699060

Email david.steel@chs.northy.nhs.uk
Background/aims: To evaluate retrospectively the clinical outcomes of patients presenting with submacular hemorrhage (SMH) secondary to neovascular age-related macular degeneration (nAMD), treated by vitrectomy, submacular tissue plasminogen activator (tPA) injection and pneumatic displacement of SMH with air followed by postoperative intravitreal ranibizumab (RZB).

Methods: Patients with SMH and nAMD had 25-guage vitrectomy and subretinal tPA (12.5 micrograms/0.1 mL) with fluid/air exchange. Intravitreal RZB was administered postoperatively to patients eligible for National Health Service (NHS) funded treatment.

Results: Of the total of 16 patients, 11 (68.7\%) had complete displacement of SMH. The remaining five had residual SMH, mainly subretinal pigment epithelium in location. Three of the four patients who previously had a failed expansile gas pneumatic displacement were successfully displaced with vitrectomy surgery. At presentation 5/16 (31.3\%) patients were eligible for NHS funded intravitreal RZB. This increased to 12 patients after the vitrectomy procedure $(75.0 \%)$ At 6 months postoperatively all improved by $\geq 1$ line. Ten of the 16 patients $(63 \%)$ improved by $\geq 2$ lines, with 10 of the 12 patients ( $83 \%$ ) treated with RZB improving by $\geq 2$ lines.

Conclusion: Vitrectomy/subretinal tPA/air to displace SMH followed by intravitreal RZB injection can stabilize/improve vision in patients with nAMD. This technique displaces hemorrhage not displaced by attempted expansile gas techniques.

Keywords: submacular hemorrhage, neovascular age-related macular degeneration, vitrectomy, tissue plasminogen activator, ranibizumab

\section{Introduction}

Patients with submacular hemorrhage (SMH) associated with neovascular age-related macular degeneration (nAMD) generally have a poor visual prognosis. ${ }^{1-4}$ This is thought to be due to physical separation of the retinal pigment epithelium (RPE) from the retina, shear stress on the photoreceptors from fibrin retraction and iron related toxicity to the RPE and choriocapillaris. ${ }^{5,6}$ Treatment with vascular endothelial growth factor (VEGF) inhibitors has transformed the prognosis of nAMD, but in the past, patients with $\mathrm{SMH}$ were excluded from major clinical trials and evidence for their efficacy in these patients is lacking. ${ }^{7,8}$ Some patients with SMH in the UK are also excluded from National Health Service funded ranibizumab (RZB) treatment by visual eligibility criteria. ${ }^{9}$

Whilst surgical removal of SMH has been shown to be ineffective at preserving vision, ${ }^{10}$ two less traumatic techniques for displacing SMH away from the fovea have been described. The 'expansile gas technique' utilizes pneumatic displacement of SMH 
by the intravitreal injection of expansile gas combined with intravitreal tissue plasminogen activator (tPA) and face downward posture postoperatively. ${ }^{11-17}$ An alternative technique, called here the 'vitrectomy technique', involves vitrectomy with subretinal tPA injection and air exchange. ${ }^{18,19}$

Studies have been published assessing the effectiveness of the expansile gas technique combined with anti-VEGF agents for preserving vision in $\mathrm{nAMD}$ associated with $\mathrm{SMH} .{ }^{20-22}$ Advantages for the vitrectomy technique include a lesser requirement for posturing, better displacement of blood and less direct shear stress on photoreceptors because of direct hemorrhage lysis by subretinal tPA as compared to the expansile gas technique. ${ }^{18,19}$ Vitrectomized eyes may however be associated with altered pharmacokinetics of RZB with greater dissipation and therefore reduced effectiveness of the anti-VEGF action.

We have been treating patients presenting with large thick SMH associated with nAMD in patients who have posturing difficulty with vitrectomy and subretinal tPA followed by postoperative intravitreal RZB and carried out a retrospective analysis of our results.

\section{Methods}

Consecutive patients presenting to Sunderland Eye Infirmary, UK, between August 2007 and December 2008 with SMH secondary to nAMD, were treated with 25-gauge vitrectomy, subretinal tPA and air to displace $\mathrm{SMH}$ away from the foveal center. Patients were treated if the following criteria were met: a clear history of suddenly reduced vision within 6 weeks; the presence of thick SMH involving the foveal center obscuring the RPE and choroidal patterns and appearing dark red or black with visible elevation; a total extent of blood of at least 3 disc diameters in greatest linear dimension; signs of nAMD in the effected eye and/ or in the fellow eye (drusen, pigmentary change or nAMD); patients were unable to comply with the postoperative face down posturing requirements of an expansile gas technique (ie, unable to maintain a face downward position for 48 hours), or who had previously failed displacement using an expansile gas technique.

Patients with a vitreous hemorrhage obscuring the fundus were excluded as were patients with massive hemorrhage measuring more than 12 disc diameters in greatest linear dimension.

Vitrectomy was carried out using the Alcon Accurus ${ }^{\circledR}$ 25 g system (Alcon Laboratories, Fort Worth, TX, USA). Core vitrectomy was performed, and if no posterior vitreous detachment was present, this was not induced unless vitreomacular traction was present preoperatively (one patient). An existing posterior vitreous detachment was present in eight patients. Subretinal tPA was injected at a concentration of 12.5 micrograms in $0.1 \mathrm{~mL}$ with a 41 -gauge needle at $1-4$ points over the surface of the SMH away from the fovea as previously described. ${ }^{18,19}$ Volumes injected ranged from $0.05 \mathrm{~mL}$ to $0.15 \mathrm{~mL}$. Fluid/air exchange was performed at the end of surgery. No gas was exchanged. No specific posturing instructions were given for daytime but the patient was told to sleep with three pillows on the side of the effected eye at night. Seven patients were pseudophacic at the time of vitrectomy surgery and a further 3 had cataract surgery during the first year of follow up when they developed visually significant lens opacities. All surgery was carried out under local anesthesia by a single surgeon (DHWS).

Patients were reviewed 1 day and 1 week postoperatively. Visual acuity (VA) was assessed at the 1 week visit and $0.05 \mathrm{~mL}$ of intravitreal RZB was given to all patients whose vision was logarithm of the minimum angle of resolution (logMAR) $1.20(6 / 96)$ or better at 1 week following initial surgery. The RZB injection was then repeated at monthly intervals until 3 doses had been given. Further RZB was given depending on clinical response as per the National Institute for Health and Clinical Excellence (NICE)/Royal College of Ophthalmologist guidelines. ${ }^{23}$

At each visit, the patient underwent best-corrected Snellen best corrected visual acuity (BCVA) measurements. This was converted to and expressed as $\log$ MAR for subsequent analysis. Count fingers vision was recorded as logMAR 2 and hand movements as $\log$ MAR 3. A biomicroscopic fundus examination, color photography and optical coherence tomography (OCT) were carried out at each visit. The greatest linear dimension of SMH using disc diameters was assessed from preoperative photography. Success of the procedure in displacing hemorrhage away from the fovea at 1 week and BCVA at 1, 6 and 12 months were used as outcome measures. The numbers of intravitreal RZB injections in the 12 months of follow up were recorded.

Applicable institutional and governmental regulations were followed during this research. The study was classified as a service evaluation by the local ethics committee and as such did not require formal ethical approval.

\section{Results}

Of 16 patients presenting, and meeting the criteria, 10 were female patients. The mean age was 81 years (range: 76-88). The mean time from surgery to symptoms of reduced vision was 15 days (range: 3 days-6 weeks). Four patients had 
a previously failed attempt at expansile gas displacement. Three other patients had a history of previous eye problems: superotemporal branch retinal vein occlusion (logMAR VA 0.48 ); macular hole surgery (logMAR 0.30$)$; previous bevacizumab (BZB) injections prior to the onset of SMH (logMAR 0.48 prior to $\mathrm{SMH}$ ).

Five of the 16 (31\%) patients with SMH were eligible for intravitreal RZB based on vision criteria (logMAR 1.20 or better) at presentation. This increased to 12 patients after the displacement procedure (75\%). Four patients did not receive intravitreal RZB as their vision did not improve to $6 / 96$ or better after vitrectomy surgery.

Follow up was available on 16 patients at 1 and 6 months and 10 patients at 12 months ( 3 died and 3 were lost to follow up).

Presenting $\log$ MAR VA ranged from 0.78 to 3.00 with a mean preoperative logMAR VA of 1.81 (95\% confidence interval [CI]: 1.38 to 2.24). Subgroup analysis of logMAR VA of those treated with RZB improved to 0.58 (95\% CI: 0.43 to 0.74 , when compared to baseline $P<0.001$ ), 0.69 (95\% CI: 0.46 to $0.91, P<0.001)$ and 0.66 (95\% CI: 0.46 to $0.87, P=0.001)$ at 1, 6 and 12 months postoperatively respectively, Figure 1 . Subgroup analysis of $\log$ MAR VA of those not treated with RZB were not statistically different from baseline $(P \geq 0.10)$. There was no difference in age between those treated with RZB and those not $(P=0.50)$. However, there was a difference in duration of symptoms for those treated with RZB (10.7 days, 95\% CI: 7.4 to 13.9 ) and those not (28.3 days, 95\% CI: 10.7 to $45.8, P<0.001$ ). Median duration of symptoms was 12.5 days. Those presenting with less duration than this had a trend for better a 12 month logMAR VA outcome than those presenting later but was not statistically significant $(0.58$ vs 0.85 , $P=0.19)$. At 6 months postoperatively 10 of the original 16 patients $(63 \%)$ had improved by $\geq 2$ lines. Ten of the 12 patients (83\%) treated with RZB improved by $\geq 2$, and all improved by $\geq 1$ line. The mean number of lines of improvement was 3.4 at 6 months postoperatively.

The mean greatest linear diameter (GLD) of SMH was 6 disc diameters (range: $3-12$ ). In the 12 patients who were eligible for RZB after surgery, the mean GLD of SMH was 5 disc diameters (range: 4-9). The four patients who were ineligible had a mean GLD of 8.5 disc diameters (range: 6-12). Median GLD was 5.5. Those presenting with less GLD than this had a trend for better a 12 month logMAR VA outcome than those presenting later but was not statistically significant ( 0.59 vs $0.78, P=0.34$ ).

The mean number of RZB injections given to those with eligible VA after surgery was 3.7 injections at 6 months.
At 12 months the mean number of injections was 4.5 (range: $3-8$ ).

Eleven of the $16(69 \%)$ patients had complete displacement of SMH. Five of the $16(31 \%)$ patients had residual SMH which was mainly sub-RPE in location. In all patients treated with RZB after displacement, nAMD was evident on either slit lamp biomicroscopy or fluorescein angiography. Three of the four patients who previously had a failed pneumatic displacement were successfully displaced with vitrectomy surgery. One of the 16 patients had a small foveal retinal dehiscence when injecting tPA. No patient had intraoperative retinal breaks or postoperative retinal detachments.

No patient experienced a significant vitreous hemorrhage postoperatively, however 2 patients given RZB experienced a recurrent SMH postoperatively. One patient with a mild hemorrhage at 4 months was treated with further lucentis, the other had a major SMH at 2 months involving the entire temporal retina reducing the vision to perception of light. This patient was treated with 180-degree retinotomy, SMH removal and an RPE patch and regained vision to logMAR 1.25 (initial vision $\log$ MAR 3.00, hand movements, vision after displacement, LogMAR 0.78).

\section{Discussion}

It is not uncommon for patients with nAMD to develop SMH that has a significantly worse visual prognosis. ${ }^{1-4}$ In one study approximately $40 \%$ of patients with pigment epithelial detachments developed SMH during the course of their disease.$^{24}$ Furthermore, treatment with VEGF inhibitors is possibly associated with an increased incidence of SMH in certain subtypes of nAMD. ${ }^{25}$ In a study by Goverdhan and Lochhead, $40 \%$ of patients with large occult choroidal neovascularization (CNV) developed SMH after treatment with BZB. ${ }^{26}$ Unfortunately patients with SMH were excluded from all the recent major anti-VEGF trials and the management of such patients is therefore not guided by randomized controlled trial evidence. ${ }^{78}$ Indeed, there is no consensus regarding optimal treatment in patients with $\mathrm{SMH}$ associated with nAMD.

One of the arms of the large submacular surgery trials carried out in the USA in the 1990s evaluated the efficacy of removing SMH with vitrectomy surgery. Unfortunately the procedure did not improve the visual outcomes compared to observation alone, probably for two main reasons. Firstly, direct surgical removal of hemorrhage resulted in retinal and RPE trauma, and secondly no treatment was given for the underlying choroidal neovascular membrane (CNVM). There was also a high postoperative retinal detachment rate. ${ }^{10}$ 


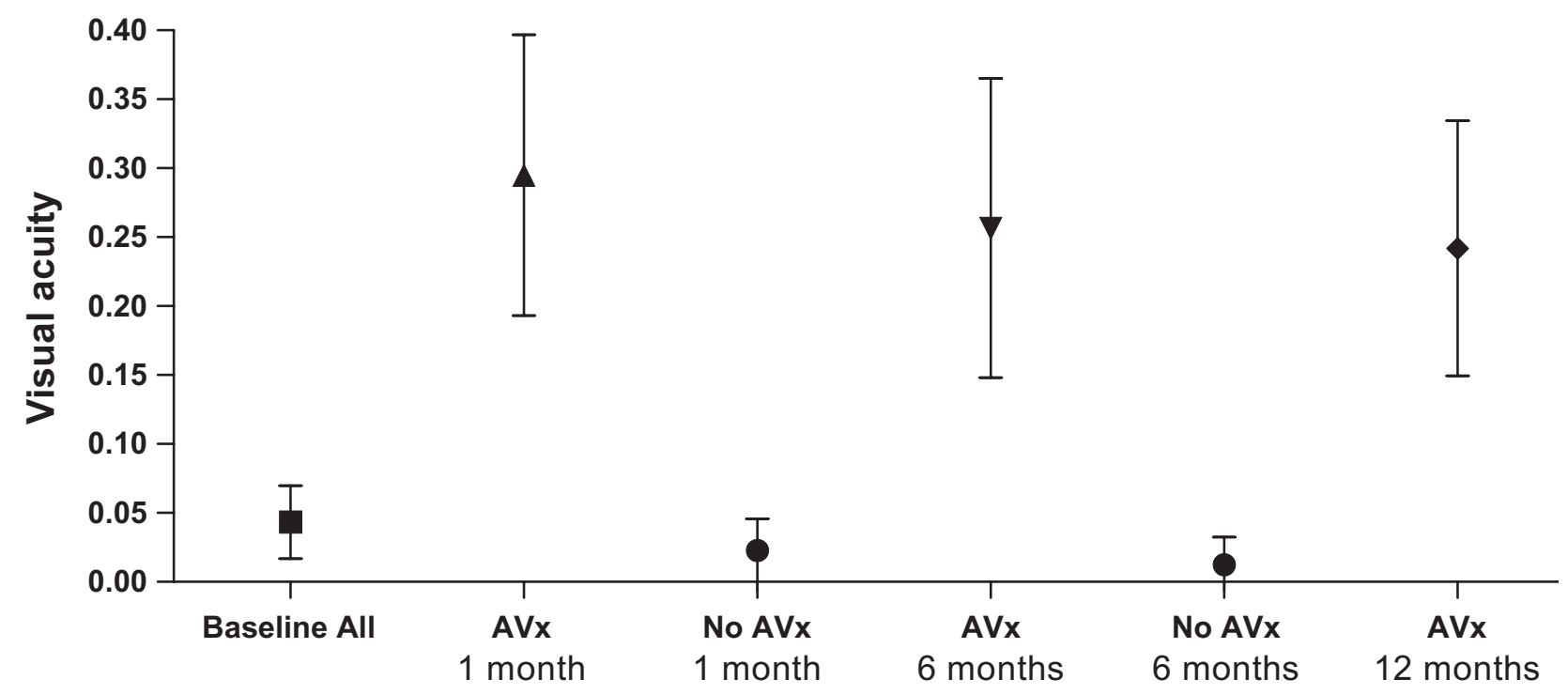

Figure I Mean visual acuity (with $95 \%$ confidence intervals), from baseline and following vitrectomy + subretinal $t P A$, with $(n=12)$ or without $(n=4)$ ranibizumab treatment.

Abbreviations: $\mathrm{AVx}$, vascular endothelial growth factor inhibitors; tPA, tissue plasminogen activator.

Techniques have subsequently been described to pneumatically displace SMH from the foveal area, without actual removal. The most widespread technique described is using an intravitreally injected expansile bubble of gas combined with clot lysis using intravitreally injected tPA ('expansile gas displacement'). ${ }^{11-17}$ Several papers have evaluated the efficacy of this relatively simple technique and described high success rates in terms of SMH displacement. ${ }^{12-17}$ Visual acuity improved in the short term but not longer because of the effect of recurrent $\mathrm{CNVM}$ growth. ${ }^{14}$ Clinicians are now starting to use these techniques combined with anti-VEGF to treat the underlying CNVM..$^{20-22}$ Meyer et $\mathrm{al}^{20}$ described a series of 19 eyes who were treated with 'expansile displacement' and BZB. They reported a mean visual acuity improvement of 3.7 lines by 12 weeks postoperatively and successful displacement of the SMH in 17 of the 19 patients.

The treatment protocol carried out in our series for this particular group of patients resulted in a sustained improvement in vision in 12 of the 16 patients. The technique of vitrectomy, subretinal tPA and air was effective in completely displacing SMH away from the fovea in $69 \%$ of the patients despite no specific daytime posturing instructions being given in a selected group of patients who were unable to comply with strict posturing requirements. It was also effective in 3 patients who had a previously failed expansile gas procedure. The mean age of the patients treated was 81 years and highlights the difficulty of posturing in older patients who often have multiple health problems. Lincoff et al have recently demonstrated that optimum displacement of SMH after expansile gas displacement is achieved with only a 40 degree forward face tilt downwards, with full face down positioning not needed ${ }^{27}$ However, even this position can be arduous for elderly patients to maintain.

The effectiveness of the vitrectomy technique compared to an expansile gas technique in patients who can posture is unknown but it has been suggested that the former results in less shear stress on photoreceptors because of direct hemorrhage lysis by subretinal tPA prior to displacement as compared to intravitreally injected tPA with limited transretinal diffusion ability. ${ }^{28,29}$ Furthermore, a recent study showed vitrectomy and gas with subretinal tPA was more effective at displacing SMH than vitrectomy and gas with intravitreal tPA, suggesting the former effectively lyses clot. ${ }^{30}$ It is also possible vitrectomy may have other advantages in the treatment of nAMD. Previous authors have noted an association between nAMD and vitreous attachment with the presence of occult vitreomacular traction on $\mathrm{OCT}^{31,32}$ Vitreoretinal separation induced either at the time of surgery or postoperatively may have a positive effect on retinal function. It is also possible the increased retinal oxygenation present after vitrectomy may have a positive effect on the course of nAMD ${ }^{33,34}$ Conversely, vitrectomy can alter the pharmacokinetics of intravitreally injected drugs, reducing their half life and hence potentially reducing their effectiveness. ${ }^{35,36}$ For this reason we deliberately limited the amount of vitrectomy and only induced a posterior vitreous detachment when vitreomacular traction was present on OCT preoperatively. Recently the use of subretinal BZB has been described with the vitrectomy technique to increase the efficacy of the 
initial dose of the anti-VEGF. ${ }^{37}$ Subsequent doses still have to be given intravitreally however and the intravitreal RZB we used still appeared to be effective in controlling CNVM associated retinal dysfunction and scarring. We had no patients who had recurrent SMH before their first injection but 2 patients developed SMH later. It is uncertain whether this relates to the vitrectomy procedure reducing the efficacy of the RZB. SMH has been described after nonvitrectomized patients treated with anti-VEGFs ${ }^{25,26}$ and both RZB and BZB have been implicated. ${ }^{38,39}$ In all patients, where displacement was effective and accurate postdisplacement fundus assessment was possible, there were signs of active nAMD present. This contrasts with previous reports of patients presenting with AMD associated SMH where no CNVM were found after displacement, perhaps relating to the selected study population.

The vitrectomy technique used did not displace SMH in all patients, particularly those with extensive sub-RPE hemorrhage, as opposed to subretinal, and patients who appeared to have significant amounts of older SMH despite a short history of reduced vision. Furthermore previous studies have suggested the best visual results are obtained in patients with SMH of less than 1-2 weeks duration even if the surgery is successful in terms of moving blood away from the fovea. ${ }^{17}$ There are also many other potential problems, as with any technique of hemorrhage displacement. SMH situated mainly superior to the fovea could potentially be made worse by inferior displacement. Recurrent SMH can occur. ${ }^{18,19,40}$ There can be retinotoxic effects from tPA. ${ }^{41-43}$ Postoperative complications such as vitreous hemorrhage $(8 \%)$ or retinal detachment (3\%) can also occur. ${ }^{40}$

An important question therefore is: how does the technique of hemorrhage displacement followed by anti-VEGF compare to treatment with anti-VEGF alone? This has been described in case series with results better than the natural history. ${ }^{44,45}$ In particular, Stifter et al describe 21 eyes with SMH treated with BZB alone. ${ }^{45}$ At 4 months follow up, 71\% of the eyes had visual acuity within 1 line of baseline or better, with $38 \%$ improving by at least 1 line. Sacu et al describe a retrospective series of patients with SMH $(n=20)$ treated with expansile gas displacement combined with anti-VEGF treatment and compared them to a series of patients $(n=10)$ who refused gas injection and were treated with anti-VEGF therapy alone. ${ }^{21}$ At 4 months, they found with expansile gas displacement, visual acuity improved in $80 \%$ compared to $60 \%$ in the anti-VEGF alone treatment group.

In conclusion, vitrectomy with subretinal tPA and air to displace SMH followed by intravitreal RZB can improve vision and lead to regression of CNVM in patients with
nAMD. The technique can displace hemorrhage which has not been displaced previously by pneumatic gas displacement techniques but does not displace sub-RPE or old hemorrhage. Our results compare favorably to natural history studies and patients treated with anti-VEGF agents alone, and are comparable to those treated with expansile gas displacement and anti-VEGF agents. Randomized controlled trials however are required to determine the optimum management of patients presenting with SMH secondary to nAMD.

\section{Disclosure}

None of the authors has a financial or proprietary interest in any material or method mentioned.

\section{References}

1. Avery R, Fekrat S, Hawkins B, et al. Natural history of subfoveal subretinal hemorrhage in age-related macular degeneration. Retina. 1996;16:183-189.

2. Bennett SR, Folk JC, Blodi CF, et al. Factors prognostic of visual outcome in patients with subretinal hemorrhage. Am J Ophthalmol. 1990;109:33-37.

3. Scupola A, Coscos G, Soubrane G, et al. Natural history of macular subretinal hemorrhage in age-related macular degeneration. Ophthalmologica. 1999;213:97-102.

4. Chen WL, Liu JH, Lee FL. Natural course of submacular hemorrhage. Zhonghua Yi Xue Za Zhi Taipei. 1999;62(5):268-277.

5. Glatt H, Machemer R. Experimental subretinal hemorrhage in rabbits. Am J Ophthalmol. 1982;94:762-773.

6. Toth C, Morse L, Hjelmeland L, et al. Fibrin directs early retinal damage after experimental subretinal hemorrhage. Arch Ophthalmol. 1991;109:723-729.

7. Brown DM, Kaiser PK, Michels M, et al. ANCHOR study group. Ranibizumab versus verteporfin for neovascular age-related macular degeneration. N Engl J Med. 2006;355:1432-1444.

8. Rosenfield PJ, Brown DM, Heier JS, et al. MARINA study group. Ranibizumab for neovascular age-related macular degeneration. $N E n g l$ J Med. 2006;355:1419-1431.

9. National Institute for Health and Clinical Excellence: Pegaptanib and ranibizumab for the treatment of age-related macular degeneration. Available from: http://guidance.nice.org.uk/TA155. Accessed Sep 25, 2009.

10. Bressler NM, Bressler SB, Childs AL, et al. Submacular Surgery Trials (SST) Research Group: surgery for hemorrhagic choroidal neovascular lesions of age-related macular degeneration: ophthalmic findings: SST report no. 13. Ophthalmology. 2004;111:1993-2006.

11. Heriot W. Intravitreal gas and rtPA: an outpatient procedure for subretinal hemorrhage. Vail Vitrectomy Meeting 1996: 10-15 March, Vail, Colorado.

12. Hesse L, Schmidt J, Kroll P. Management of acute submacular hemorrhage using recombinant tissue plasminogen activator and gas. Graefes Arch Clin Exp Ophthalmol. 1999;237(4):273-277.

13. Hassan AS, Johnson MW, Schneiderman TE, et al. Management of submacular hemorrhage with intravitreous tissue plasminogen activator injection and pneumatic displacement. Ophthalmology. 1999;106(10): 1900-1906; discussion 1906-1907.

14. Lincoff H, Kreissig I. Intravitreal injection of tissue plasminogen activator and gas in subretinal hemorrhage caused by age-related macular degeneration. Retina. 2001;21:191.

15. Schulze SD, Hesse L. Tissue plasminogen activator plus gas injection in patients with subretinal hemorrhage caused by age-related macular degeneration: predictive variables for visual outcome. Graefes Arch Clin Exp Ophthalmol. 2002;240:717-720. 
16. Krepler K, Kruger A, Tittl M, et al. Intravitreal injection of tissue plasminogen activator and gas in subretinal hemorrhage caused by age-related macular degeneration. Retina. 2000;20(3):251-256.

17. Hattenbach LO, Klais $\mathrm{C}$, Koch FH, et al. Intravitreous injection of tissue plasminogen activator and gas in the treatment of submacular hemorrhage under various conditions. Ophthalmology. 2001;108(8):1485-1492.

18. Haupert CL, McCuen BW 2nd, Jaffe GJ, et al. Pars plana vitrectomy, subretinal injection of tissue plasminogen activator, and fluid-gas exchange for displacement of thick submacular hemorrhage in age-related macular degeneration. Am J Ophthalmol. 2001;131(2):208-215.

19. Olivier S, Chow DR, Packo KH, et al. Subretinal recombinant tissue plasminogen activator injection and pneumatic displacement of thick submacular hemorrhage in age-related macular degeneration. Ophthalmology. 2004;111(6):1201-1208.

20. Meyer CH, Scholl HP, Eter N, et al. Combined treatment of acute subretinal haemorrhages with intravitreal recombined tissue plasminogen activator, expansile gas and bevacizumab: a retrospective pilot study. Acta Ophthalmol Scand. 2008;86(5):490-494.

21. Sacu S, Stifter E, Vécsei-Marlovits PV, et al. Management of extensive subfoveal haemorrhage secondary to neovascular age-related macular degeneration. Eye. 2009;23(6):1404-1410.

22. Hasler PW, La Cour M, Villumsen J. Pnuematic displacement and intravitreal bevacizumab in the management of subretinal haemorrhage caused by choroidal neovascularization. Acta Ophthalmol Scand. 2007;85:577-578.

23. The Royal College of Ophthalmologists. Ranibizumab: the clinician's guide to commencing, continuing and discontinuing treatment. Available from: http://www.rcophth.ac.uk/docs/scientific/Ranibizumab_June_ 2008.pdf. Accessed on Sep 25, 2009.

24. Poliner LS, Oik RJ, Burgess D, et al. Natural history of retinal pigment epithelial detachments in age-related macular degeneration. Ophthalmology. 1986;93(5):543-551.

25. Baeteman C, Hoffart L, Galland F, et al. Subretinal hemorrhage after intravitreal injection of anti-VEGF for age-related macular degeneration: a retrospective study. J Fr Ophtalmol. 2009;32(5):309-313.

26. Goverdhan SV, Lochhead J. Submacular haemorrhages after intravitreal bevacizumab for large occult choroidal neovascularisation in age-related macular degeneration. Br J Ophthalmol. 2009;92(2):210-212.

27. Lincoff H, Kreissig I, Stopa M, Uram D. A 40 degrees gaze down position for pneumatic displacement of submacular hemorrhage: clinical application and results. Retina. 2008;28(1):56-59.

28. Kamei M, Misono K, Lewis H. A study of the ability of tissue plasminogen activator to diffuse into the subretinal space after intravitreal injection in rabbits. Am J Ophthalmol. 1999;128(6):739-746.

29. Lewis H. Intraoperative fibrinolysis of submacular hemorrhage with tissue plasminogen activator and surgical drainage. Am J Ophthalmol. 1994;118(5):559-568.

30. Hillenkamp J, Surguch V, Framme C, et al. Management of submacular hemorrhage with intravitreal versus subretinal injection of recombinant tissue plasminogen activator. Graefes Arch Clin Exp Ophthalmol. Epub 2009 Aug 11.
31. Lee SJ, Lee CS, Koh HJ. Posterior vitreomacular adhesion and risk of exudative age-related macular degeneration: paired eye study. Am J Ophthalmol. 2009;147(4):621.e1-626.e1.

32. Mojana F, Cheng L, Bartsch DU, et al. The role of abnormal vitreomacular adhesion in age-related macular degeneration: spectral optical coherence tomography and surgical results. Am J Ophthalmol. 2008;146(2):218-227.

33. Stefánsson E. Physiology of vitreous surgery. Graefes Arch Clin Exp Ophthalmol. 2009;247(2):147-163.

34. Williamson TH, Grewal J, Gupta B, et al. Measurement of PO2 during vitrectomy for central retinal vein occlusion, a pilot study. Graefes Arch Clin Exp Ophthalmol. 2009;247(8):1019-1023.

35. Chin HS, Park TS, Moon YS, Oh JH. Difference in clearance of intravitreal triamcinolone acetonide between vitrectomized and nonvitrectomized eyes. Retina. 2005;25(5):556-560.

36. Doft BH, Weiskopf J, Nilsson-Ehle I, Wingard LB Jr. Amphotericin clearance in vitrectomized versus nonvitrectomized eyes. Ophthalmology. 1985;92(11):1601-1605.

37. Treumer F, Klatt C, Roider J, Hillenkamp J. Subretinal co-application of recombinant tissue plasminogen activator and bevacizumab for neovascular age-related macular degeneration with submacular hemorrhage. Br J Ophthalmol. Epub 2009 Nov 27.

38. Krishnan R, Goverdhan S, Lochhead J. Submacular haemorrhage after intravitreal bevacizumab compared with intravitreal ranibizumab in large occult choroidal neovascularization. Clin Experiment Ophthalmol. 2009;37(4):384-388.

39. Karagiannis DA, Mitropoulos P, Ladas ID. Large subretinal haemorrhage following change from intravitreal bevacizumab to ranibizumab. Ophthalmologica. 2009;223(4):279-282.

40. Chen CY, Hooper C, Chiu D, et al. Management of submacular hemorrhage with intravitreal injection of tissue plasminogen activator and expansile gas. Retina. 2007;27(3):321-328.

41. Vote BJ, Buttery R, Polkinhorne PJ. Endophthalmitis after intravitreal injection of frozen prepared tissue activator (tPA) for pneumatic displacement of submacular hemorrhage. Retina. 2000;20(3):251-256.

42. Mali RS, Cheng M, Chintala SK. Plasminogen activators promote excitotoxicity-induced retinal damage. FASEB J. 2005;19(10): 1280-1289.

43. Chen SN, Yang TC, Ho CL, et al. Retinal toxicity of intravitreal tissue plasminogen activator: case report and literature review. Ophthalmology. 2003;110(4):704-708.

44. Soliman W, Lund-Anderson H, Larsen M. Resolution of subretinal haemorrhage and fluid after bevacizumab in aggressive peripapillary subretinal neovascularization. Acta Ophthalmol Scand. 2006;84:707-708.

45. Stifter E, Michels S, Prager F, et al. Intravitreal bevacizumab therapy for neovascular age-related macular degeneration with large submacular hemorrhage. Am J Ophthalmol. 2007;144(6):886-892.
Clinical Ophthalmology

\section{Publish your work in this journal}

Clinical Ophthalmology is an international, peer-reviewed journal covering all subspecialties within ophthalmology. Key topics include: Optometry; Visual science; Pharmacology and drug therapy in eye diseases; Basic Sciences; Primary and Secondary eye care; Patient Safety and Quality of Care Improvements. This journal is indexed on Submit your manuscript here: http://www.dovepress.com/clinical-ophthalmology-journal

\section{Dovepress}

PubMed Central and CAS, and is the official journal of The Society of Clinical Ophthalmology (SCO). The manuscript management system is completely online and includes a very quick and fair peer-review system, which is all easy to use. Visit http://www.dovepress.com/ testimonials.php to read real quotes from published authors. 